Journal of Urban Design

\title{
Integrative Spatial Quality: A Relational Epistemology of Space and Transdisciplinarity in Urban Design and Planning
}

\author{
AHMED Z. KHAN (a), FRANK MOULAERT (b), JAN SCHREURS (b) \& KONRAD \\ MICIUKIEWICZ (c)
}

(a) Department of Building, Architecture \& Town Planning (BATir), Universite Libre de Bruxelles, Brussels, Belgium

(b) Planning and Development Unit, University of Leuven (KU Leuven), Leuven, Belgium

(c) School of Architecture, Planning and Landscape, Newcastle University, UK

\section{Introduction: An Integrative Approach to Understanding Spatial Quality}

Spatial quality is a central tenet and, at the same time, a highly contentious issue in the urban design and planning field. This is the case for practitioners, academics and researchers alike. Underpinning the canonical texts (e.g. Sitte [1889] 1965; Lynch 1960, 1981; Cullen 1961; Bacon 1974; Alexander et al. 1977, etc.) and even some major recent contributions in defining the theoretical foundations of the field (Sternberg 2000; Banerjee 2001; Madanipour 2006; Carmona 2014), is a broad consensus on the importance of spatial quality as a normative quest that runs through the theories, principles and methods of the field. Yet, different users, professional and research communities tend to have very different views on what makes a particular organization of space 'qualitative' or not (e.g. Madanipour 2006; Ewing and Handy 2009; Mehta 2014). A universal understanding of the concept 'spatial quality' does not exist, except as shorthand for either the intention to invest some 'extra' (talent, care, aesthetics, money, etc.), or to stress a 'normative' attitude and endeavour. Yet when addressing spatial quality within theoretical elaborations or professional operations, different spatial quality preferences cannot just be 'added up' when mobilizing this notion.

In the study of spatial quality ${ }^{1}$ therefore, it is important to give the concept a relational and integrative character, with a diversity of spatial quality dimensions and enhancing practices cohering into it. While mobilizing the integrative potential of spatial quality for urban design and planning through a relational understanding - linking 'quality' to uses and users within a multi-dimensional context - the aim of the themed issue is to lay out in a coherent way the theoretical foundations of the field (Moulaert et al. 2013; Khan, Moulaert, and Schreurs 2013).

Urban design can be seen as a field that engages and enquires into "the human experience that the built environment evokes" (Sternberg 2000, 266) throughout oppositional realms (from private properties to the public realm) and across scales (from the street to the regional landscape). This experiential quality of the built environment and landscapes has been characterized by diverse attributes such as: comfort, human scale, variety, complexity,

\footnotetext{
${ }^{1}$ Four of the papers in this themed issue emanate from the SPINDUS: 'Spatial Innovation, Planning, Design and User Involvement' strategic basic research project funded by the Flemish Agency for Science \& Technology, IWT-SBO (Project IWT 090080). SPINDUS ran from December 2009 until November 2013 and aimed to develop practical and pedagogical planning and urban design methods to assess, evaluate, and implement spatial quality. For more info on the research project: www.spindus.org,http://www.spindus.org
} 
urbanity, inclusiveness, meaningfulness, understandability, linkage and coherence, congeniality, playfulness, safety and security, transparency, mystery and awe, and so on (cf. overviews of attributes by scholars from Kevin Lynch to more recent contributions; see Moulaert et al. 2013). However, these attributes are the outcome of complex socio-spatial, cognitive and psychological naming and framing, and cannot be estranged from their particular socio-economic, historical, environmental and local but also wider spatial cultural contexts (Khan, Moulaert, and Schreurs 2013). Nonetheless, addressing them is considered to be the core ambition and aim of 'urban design', a field that Matthew Carmona (2014) has rightly identified as a 'mongrel discipline', that according to Jose ' Louis Sert emerged out of the will "to find the common base for the joined work of the Architect, the Landscape Architect, and the City Planner" while being wider than the scope of these three professions (Krieger 2009, 114), and has been praised "as an integrative force, deliberately straddling and helping to connect the silo-based disciplines of the past" (Bentley 1998, 15). This resonates with recent discourse about the "vagueness" of urban design (Inam 2002, 35), about multiple challenges and contradictory normative concerns (Madanipour 2006), the absence of a dedicated intellectual "core" and of cohesive "theoretical foundation" (Cuthbert 2011, 94) and, in particular, the lack of a cohesive and robust "diagnostic and analytical apparatus" of the discipline (Marshall 2012, 268). However, while major attempts have been made to address these profound issues (Sternberg 2000; Loukaitou-Sideris 2012; Carmona 2014), a series of thoughtful reflections have pleaded to also broaden the scope of urban design, stating that programming and use of public space are as important as its physical design (Southworth 2014) and underscoring the importance of addressing new challenges related to sustainability, climate change, sea level rise, large-scale transportation infrastructure, etc. (Barnett 2014).

Aware of the ongoing debate on the need of both focus and broader scope in urban design, 'integrative spatial quality' is proposed as an imperative and a normative concept for further developing the analytical and diagnostic capabilities in the discipline. Integrative spatial quality can be seen as a magnetic force improving the intellectual cohesiveness of the discipline, yet broadening its scope by engaging with the diversity of issues and challenges of the design for the ecological age (Khan, Vandevyvere, and Allacker 2013). This implies conceptualizing the terms of spatial quality across scales, beyond shape and, more importantly, across and beyond disciplines (e.g. architecture, spatial planning, geography, sociology, ecology, etc.). Understanding and creating integrative spatial quality needs a relational and transdisciplinary understanding. This requires to first draw attention to the concepts and dimensions of space that various actors mobilize in their respective spatial practices and imaginations, and second to build relationships between these through a 'relational epistemology of spatial quality' that opens possibilities for valuing spatial knowledge from all types of users and uses (Khan, Moulaert, and Schreurs 2013).

A cohesive intellectual core and a broadened substantive scope of urban design can be seen as two sides of the same coin. The following two main sections of this introductory paper address the value of integrative spatial quality for urban design and broaden its scope. The first section presents the theoretical basis of the argument built on a relational epistemology of space and spatial qualities, an excursion on transdisciplinarity and a meta-framework for developing a multi-dimensional and integrative diagnostic of spatial qualities and analytical capabilities to do so. The second section offers a number of perspectives by papers in this themed issue that 
highlight the ways in which the concern for an integrative view of spatial quality points towards the broadening of the theoretical core of the discipline of urban design.

\section{The Value of Integrative Spatial Quality for Urban Design}

Values in urban design and the spatial characteristics that enable such values are two interrelated aspects, fundamental for understanding the concept of integrative spatial quality. Many times values are called for by demanding 'well-designed environments' and 'good design' expected to deliver social, economic, aesthetic and environmental values and benefits for a diversity of stakeholders (investors, developers, designers, occupiers, public authorities and the community, see Carmona, De Magalhaes, and Edwards 2002). The issue of value becomes structurally significant when urban design is also seen as the tool for reshaping the built environment "to accommodate the new urban conditions" (Madanipour 2006, 191). The structural qualities associated with enabling/delivering these values, however, have a long history within urbanism and are often defined in terms of 'dimensions and concepts' differentiated along substantial and procedural lines of thinking. Although not defining 'spatial quality' in an explicit way, a quick review of major theoretical works shows a wide variety of these dimensions and concepts that range from imageability, human scale, enclosure, transparency, continuity and so on to liveable streets and neighbourhoods, a minimum residential density and intensity of use, integration of activities, buildings that define public spaces, and many different buildings and spaces with complex arrangements (Lynch 1960; Cullen1961; Jacobs [1961] 1974; Bacon1974; Appleyard \& Jacobs 1982; Loukaitou-Sideris 2012).

While working towards integrative spatial quality, it is important to recognize that these values can be seen from different perspectives. For example, Ali Madanipour (2006) analyzed them from the perspective of the interests of producers, regulators and users of urban space. ${ }^{2}$ However, as he argued, "the three perspectives, and differences within each perspective, can be at odds with each other, creating tensions and incompatibilities" (Madanipour 2006, 191). Seeing these values from a more integrative perspective, Ernest Sternberg (2000) proposed the thesis that the constituents of the "human experience of the built form" (Kevin Lynch's 'sensuous qualities') are 'non-commodifiable'. He proposed 'non-commodifiability' as a conceptual and 'intellectual foundation' that would seek out the integrative principles underlying the human experience of the built form. Building upon Gordon Cullen's (1961) 'art of relationships' and Edmund Bacon's (1974) 'experiential continuity', Sternberg's argument has been pertinent for urban design; it requires concepts through which one can recognize and work with the cohesive interrelationships that constitute the built environment, and the intellectual principles through which they can recognize, sustain and reconstitute environmental integrity. He identified four such principles through which urban environments

\footnotetext{
${ }^{2}$ For the producers, it reflects a new division of labour among the stakeholders, shapes the built environment, coordinates and leads the development process, stabilizes the market conditions and markets the development. For the regulators, it helps make the city more competitive, shapes the future of the city, manages its environmental change, and contributes towards good governance by bringing together different actors to participate in the process of developing and implementing a vision for the city. For the users of the city, it improves how the place functions and enhances its symbolic values, even though such values are always contested (Madanipour 2006).
} 
can transcend commodification: good form, legibility, vitality and meaning. ${ }^{3}$ More recently, in an attempt to postulate a cohesive theory of urban design as a 'place-shaping continuum', Carmona (2014) brings in 'process' as an integrative perspective on these values. He sees urban design as "a continuous integrated process or continuum" that is "informed by its historical place-based modes of operation" and "shape[s] the experience of space" through the "combined outcomes and interactions between design, development, use and management" $(2014,33)^{4}$

As an intellectual concern about not defining 'urban design too narrowly' (Barnett 2014), about the "lack of cohesive theoretical foundations" (Sternberg 2000, 265), 'normative goals' (Loukaitou-Sideris 2012) and 'the core' of urban design (Carmona 2014, 34) an 'integrative spatial quality' as a holistic and dynamic imperative is proposed. It can be seen as an imperative that cuts across the values of 'non-commodifiability' (Sternberg 2000), of central importance to 'producers, regulators and users' (Madanipour 2006), and permeates through all the 'four interrelated process dimensions' (Carmona 2014) that shape the human experience of space and built form. Integrative spatial quality is intended to work for the full range of urban design situations: from public space, historic preservation, neighborhood revitalization and community development, to largescale spatial (re)structuring, new towns and infrastructure (re)developments, sustainability and climatic change related adaptation, such as facing up to rising sea levels and carbon emissions, energy crises, depleting resources and ecosystem services, urban heat island effects, integrated coastal zones and protected areas management, and so on. Sustainability and climate change related challenges are seen as fundamentally redefining the qualities that are sought through the theory, practice and process of urban design and planning.

Indeed, if integrative spatial quality is seen as an imperative that holds the 'core' of urban design and planning together, and underpins all the processes of the production of space (shaping of urban spaces and places, i.e. the built environment), two types of fundamental questions concerning a shared approach to understanding spatial quality come to the fore: (1) 'epistemological questions' related to diagnostic and analytical methods-what type of qualities? and for whom? and how to read/identify them?; and (2) 'actors, networks, participation and transdisicplinary questions' related to the implementation of spatial qualities

\footnotetext{
3 Good form is about proportions and interrelations between parts and the whole. Legibility as an integrative principle underlying the urban inhabitant's experience of the city (Lynch's 'sensuous qualities' or simply 'sense' of place-Banerjee and Southworth 1991, 6) — through elements such as paths, edges, nodes, landmarks, districts (own identifiable character) - that is crucial in the 'interrelationship of parts into a whole'. Vitality refers to the concepts of mixed use, fine grain, high density and permeability as important sources of urban vitality that is a pervasive consideration in urban design. Meaning implies identity, local / indigenous culture, history, etc., i.e. design to make diversity cohere (Sternberg 2000, 270-275).

4 Carmona $(2014,33)$ argues that "it is necessary to understand the creation, re-creation and performance of the built environment across four interrelated process dimensions, self-consciously and un-self-consciously using design processes to knowingly and unknowingly shape place (Figure 12). Thus it is not just design, nor even development processes, that shape the experience of space, but instead the combined outcomes and interactions between: Design - the key aspirations and vision, and contextual and stakeholder influences for a particular project or set of proposals. Development - the power relationships, and processes of negotiation, regulation and delivery for a particular project or set of proposals. Space (or place) in use-who uses a particular place, how, why, when and with what consequences and conflicts. Management - the place-based responsibilities for stewardship, security, maintenance and ongoing funding. Moreover, this is not a series of discrete episodes and activities as we often attempt to understand them from our siloed standpoints, but instead a continuous integrated process or continuum from history to and through each of the place-shaping processes of today and on to tomorrow".
} 
foreseen in the diagnostic and analytical methods - how to address, implement, develop and manage those qualities and who is/should be involved? Concerning the former (1) a relational and pragmatic epistemology of space is proposed, and concerning the latter (2) transdisciplinarity is put forward as the basis for knowledge needed (Moulaert and Van Dyck 2013). Both of them underpin the formulation of a meta-framework for reading, analyzing and addressing spatial qualities.

\section{A Relational Pragmatic Epistemology of Space and Spatial Qualities}

Spatial quality is a multi-dimensional and complex phenomenon due to its dynamic and socially bounded nature (Rapoport 1970; Khan, Moulaert, and Schreurs 2013). It involves the understanding of interactions between space/ environment, its uses and users that are heavily influenced by (inter-subjective) cultures and 'socio-cultural schemata' that mediate between environment and people (Rapoport 1982, 28). From a relational pragmatic perspective, understanding space as a quality of interaction between organisms and their environment implies that spatial qualities neither reside in the objects themselves nor wholly in people's subjective feelings towards them (Bridge 2013). Space and spatial quality are produced as a result of collective place-shaping efforts (Healey 2008, 3; Carmona 2014) that involve various human and non-human actants in different relations of power through subjectivation, organization and practices of signification (Hillier 2011) performing complex interrelations and multiple space-time relational dynamics (Healey 2006). This makes spatial quality a multidimensional and complex phenomenon, which requires a relational understanding.

Epistemology of space at a general level is a concern with the nature and scope of knowledge about space (Cooper 1999; BonJour and Sosa 2003). This concern is closely intertwined with ontology of space, as the 'what' - vision on occurrence and definition of something - may be difficult to separate from the 'how' - the ways we get to know about the 'what' (Hollis 2002). However, the relationship between 'what' and 'how' of space is not fixed but constantly evolving (Massey 2005).

Theemergenceofarelationalapproachtounderstandingandconceptualizing space is due to the primary tensions between abstract concepts and experienced relationships between phenomena, and to the ambiguity between physical-spatial and social-spatial conceptualizations of space (Khan, Moulaert and Schreurs2013). What distinguishes a relational conception of space from its traditional a-relational meaning(s) is its reference to "a relation between events or an aspect of events, and thus bound to time and process", as "perceived by a person or society" (Madanipour 2013). Rather than viewing space as "a container within which the world proceeds", the relational concept of space sees it "as a coproduct of those proceedings" (Thrift, 2003, 96), as context and issue and the result of manenvironment interactions (Rapoport 1970, 1982). Rather than detached from any process, space is an integral part of social processes: space, as Lefebvre $(1991,12)$ argued, "in isolation, is an empty abstraction"; while Massey $(2005,101)$ suggested "abstract spatial form in itself can guarantee nothing about the social, political or ethical content of the relations which construct that form".

For a practical orientation to understanding space, a relational ontology combined with a pragmatic frame of reference is emphasized. Pragmatism subscribes to a practical orientation to understanding, and focuses on problems and their consequences and practical integration of knowledge involving social coordination and deliberation (Bridge 2013). In particular, the 
Deweyan pragmatism offers a view of space that is relational but one that is inflected through human 'experiencing', which has informed a well-established strand of research in deliberative and critical pragmatist urban design and planning (Forester 1999; Hoch 2007; Healey 2009; Moulaert and Mehmood 2014). Evidence of this shift towards a relational epistemology of space and a pragmatic frame of reference can be witnessed in different spatial disciplines (see Khan, Moulaert, and Schreurs 2013, 290-292; Moulaert et al. 2013, 392-401). In architecture and urban design, this shift implies understanding spatial qualities through the experiential valuation and dialectics of spatial form and social processes, which is discernable from a growing body of work (Crawford 1995; Dovey 1999; Carmona et al. 2002; Madanipour 2006, 2010; Crysler and Heynen 2012; Yaneva 2012; Khan 2013; Carmona 2014).

While the earlier modernist conception of space, and even the 'good design' debate "revolved around issues of how the form of objects could enhance the quality of life" (Margolin and Buchanan 1995, xi), the emphasis has been reversed since then. Objects remain important as a symbolic location of experience, but the focus is on the "psychological, social and cultural contexts that give meaning and value to products and the discipline of design practice" (Margolin and Buchanan 1995, xi). This reversal represents a deepening of the scope of design with an increasing focus on synthesis: the ways in which design integrates diverse spatially distributed components, diverging requirements and interests, but in passing also adds conditions leading to new consequences for use and experiencing, thus offering new possibilities for inclusive design, not to be described ex ante and often not in words (De Jong and Van der Voordt 2002, 22- 25). This way of synthesis making follows abduction-a situated logic through which designers and users of space become jointly responsible for what they learn to see (Moore and Karvonen 2008; Servillo and Schreurs 2013). Design thinking is thus seen to rely on an evolving interaction between a context or environment and competing agendas, theory and practice, and different scale levels to endow spatial interventions with an enriched substance in tune with a broader notion of spatial quality (Schreurs et al. 2006; Khan 2010). In this sense, design is not about the application of abstract knowledge but a "principal method used by society to envision how we want to live in the future" (Moore and Karvonen 2008, 30; Khan 2011).

Along with this shift in design culture, approaches of urbanism that articulate different aims and logics of spatial qualities are proliferating. Examples are 'New Urbanism' (Cozens 2008) and its reviving of traditional urban qualities; 'landscape urbanism' (Waldheim 2006) "in which landscape replaces architecture as the basic building block of urbanism" (Scheer 2011, 612); 'ecological urbanism' aiming at "more just as well as more pleasurable futures" (Mostafavi and Doherty 2010, 50); or 'infrastructural urbanism' where “form matters, but more for what it can do than for what it looks like" (Allen 1999, 57). While moving beyond the focus on three-dimensional urban form making, a growing need is felt for an integrative approach. Compliant with a relational approach this implies acknowledging the simultaneously material and social character of spatial relations and the agencies (re)producing them, addressing urban environmental issues, and a focus on inclusive and accessible public space (Madanipour 2006, 2010; Khan 2010).

The reading and assessment of the quality of a space or a place are based upon experiential value of objects and events, identified by perceiving, thinking, sensitive and socialized subjects whose socio-subjective perceptions are relational (Schreurs, 2007; Van den Broeck et al. 2013). Personal and collective interest in particular features of spatial quality depend on the nature of 
the experienced objects and events, as well as on the cultural, class, racial and gendered identities and spatial competences of experiencing subjects. Thus, through the proposition of a relational and pragmatic epistemology of space, the need for plural imagination in rethinking spatial qualities is clearly acknowledged.

\section{Inter- and Transdisciplinarity}

Building methodological capabilities for addressing space, spatial qualities and unfolding socio-spatially innovative and ecological place-making require interand transdisciplinary methods in urban design that are capable of exploring interpretive as well as transformative capacities (Khan, Moulaert, and Schreurs 2013; Servillo and Schreurs 2013). While making the case for more inter- and transdisciplinary methodologies and knowledge building in urban design, it is argued that multiple processes at different scales are involved in the construction and shaping of individual and collective preferences for spatial qualities that change and evolve over time. Therefore, understanding, analysing and addressing spatial quality require diverse analytical capabilities to diagnose the multiple processes shaping these interactions through new insights and assessment frameworks that are based on a more integrated and inter- and transdisiciplinary knowledge base.

Urban development is inherently a multi-disciplinary activity, and urban design and planning typically involve drawing on a number of disciplines. Such multi-disciplinary collaboration may also happen in research projects, where different skills and methodologies may play a specific role in the process of inquiry. Such cooperative processes, however, are limited in what they can achieve (Austin et al. 2008) and it is in interdisciplinary work that the participants cross their 'own' epistemic boundaries, to co-produce new concepts and methods (Miciukiewicz et al. 2012; Madanipour 2013; Moulaert and Cassinari 2014). Interdisciplinarity means working towards a shared analytical framework and/or methodological apparatus for joint research on the same theme between scholars coming fromdifferent disciplines and fields (Moulaert and Cassinari 2014). It aims to create a common understanding of an issue by integrating theories, concepts, methods and data into a new whole, an integrative outcome that is more than the sum ofits parts (Madanipour 2013). Rather than the multi-disciplinary contracting out of services, interdisciplinary work closely involves a range of partners, coordinates organizational frameworks, alters perspectives, revises hypotheses, generates new insights, and forms "a new community of knowers with a hybrid interlanguage" (Wagner et al. 2011, 16; Stokols et al. 2008). Training and shared experiences within a discipline may be used as resources in a dialogue with other disciplines, enabling the parties to rethink and evaluate their own assumptions and practices (Tuana 2013). Epistemic identities, therefore, by clarifying their epistemic stances to the members of their and other epistemic communities, would be seen as potential connectors for successful interdisciplinary collaboration needed in urban design (Madanipour 2013).

Widening the scope of collaboration through engaging specialists with everyday life, transdisciplinarity has emerged as a mode of cooperation between scientific analysts and professional practitioners for improving a mutual understanding of a certain phenomenon or problem and developing a shared way of addressing it (Miciukiewicz et al. 2012; Moulaert and Cassinari 2014). Largely overlapping with the integrative character of interdisciplinarity, but giving substantially more space to practice communities (Moulaert and Cassinari 2014), transdisciplinary collaboration is the stage in which 'a fundamental epistemic shift' takes place, 
in which the participating parties areable to produce a coherent reconfiguration of the situation (Austin et al. 2008, 557). This level of integration moves towards the development of metatheoretical, analytical and methodological frameworks (see the next section on 'metaframework'; Moulaert and Van Dyck 2013). Working together in multi-disciplinary research, researchers still tend to maintain their own disciplinary perspective, while in interdisciplinary research they join up their disciplinary epistemic resources but also hitherto developed interdisciplinary research approaches to develop and use an enriched conceptual perspective. Transdisciplinarity involves the members of different scientific and practice fields working together over a long period of time, which creates the possibility of producing an overarching synthesis that goes beyonda ny single framework, as exemplified by institutional research on the governance of Socio-Ecological Systems e.g. (Ostrom 2007). It also involves trans-sector collaboration, in which questions and problems are addressed through the participation of a wide range of stakeholders in society (Klein, Mitcham, and Frodeman 2010).

Transcending disciplinary and practice field silos through the integration of interdisciplinarity and transdisciplinarity implies a relational and pragmatic approach in which researchers and practitioners collaborate in a research and action process from day one (Miciukiewicz et al. 2012; Moulaert and Cassinari 2014). Such integration and collaboration may lead to innovation; often, when people from different disciplinary backgrounds are brought together, new ideas, products and practices are triggered as ingredients of strategic responses to new challenges (Madanipour 2013). Looking at spatial quality from more than one perspectivean inherent logic of and practice in urban design (cf. Gosling and Maitland 1984) - offers a dynamism, a mobility of standpoints and a multiplicity of views that can mobilize more resources and energies for making judgements and design concepts about the subject at hand. Transdisciplinary attitudes and methods prevent new outcomes from being locked into established groups or a particular situation, as well as stimulate the inclusion of unheard voices and unacknowledged forms of knowledge, practice and experience. Therefore, dynamic multiplicity and epistemic inclusiveness (Madanipour 2006, 2013) are the means of moving beyond limiting perspectives, appreciating the complexity and multiplicity of views into sociospatial dialectics, and of trying to understand and combine as many perspectives as possible while building methodologies for understanding and addressing multiple spatial qualities.

\section{A Meta-Framework for Integrative Spatial Quality}

At the heart of building a meta-framework for reading, analyzing and building spatial quality has been the main question: how to acquire the necessary knowledge to analyze, evaluate and improve spatial quality? To this purpose, extensive research on a thematic cross-reading of spatial quality within three spatial disciplines (urban design, strategic spatial planning, and social innovation in territorial development) was carried out with a focus on eight core themes reflecting the complexity of uses of space: materiality, social space, ownership and appropriation of space, typologies, scale, nature and environment, representation of space, and ethics (Moulaert et al. 2013).

Inter- and transdisciplinarity are at the core of building the meta-framework. Combining, in an interdisciplinary way, theories and methods from research by design, spatial planning and community development through social innovation, the concept of spatial quality is broadened from a purely 'adding up' of different spatial preferences, often estranged from their social context, to a relational approach that mobilizes the integrative potential of the three fields in 
reading spatial qualities. The transdisciplinary exercise of linking spatial qualities to users and their diverse uses and understandings of, as well as expectations from space, is pursued at three levels: the conceptual level, the level of applicable planning and design methodologies, as well as in case studies and the methods applied there (see Segers et al. 2013).

Building on the synergies between the three fields and on recent progress in trans- and interdisciplinary methodologies (see previous section), a metaframework is proposed that addresses the multi-dimensional nature of spatial quality as well as the methodological innovations needed to address it. Thus, the meta-framework provides leading questions that help understand how spatial qualities are produced. It also helps in determining essential elements to analyze, evaluate and improve spatial quality. In other words, the meta-framework aims to provide normative categories, theoretical insights and methodological guidelines for analyzing, assessing and improving spatial quality. The following are the seven dimensions of the meta-framework:

1. Space and uses of space are relational. The study of spatial quality is, as a consequence, also relational. Objects and non-human life are part of the relational patterns. People (physically, socially and mentally) construct places while places subjectify and objectify people as part of a multi-dimensional web.

2. A relational approach to social space cannot exist without an ethical basis. Indeed, the individual and collective relations between people (individuals and groups), and between human and non-human actors, reflect ethical positions that are sometimes shared and sometimes contested. In our spatial-relational approach, spatial justice provides the ethical basis for the theoretical and methodological advancement. This term emphasizes the spatiality of justice and injustice, and implies that understanding the relations between space and society is essential in understanding social and socioecological injustices and ways to mitigate them.

3. The relational approach put forward in this framework devotes much attention to the role of power structures and power relations as driving factors in the uses of space. This is why it also focuses on the emergence of counter movements and alternative practices that give rise to new insights and opportunities in the use of space. In this regard, the historical and geographical context from which or in which they emerge is taken into account.

4. The use of space must be read according to the various types of (interactions with) space as informed by social, cultural, physical, biological, etc. dimensions of space. They can be seen as interlinked active components or 'actants' in society-nature interactions. Different types of agency and activity within their interrelatedness should be acknowledged.

5. The relational approach includes a multi-scalar perspective, as developed in the relational geography, multi-level governance and scalar politics literature. It is based on a multi-layered and dynamic view on scale that sees places and sites within their particular relational networks and also implies the idea that spaces and places play different roles in variegating networks across time and space. Spatial relations and qualities should thus be analyzed on different scales and at different moments.

6. Despite the analytical and socio-political shortcomings of the concept, sustainable development in all its forms of existence is a significant starting point in the emergence of a shared ontology (ontogenesis) in building spatial quality. Sustainable development 
is considered as a pro-active process of (spatial) transition as emphasized in the literature on socio-ecological systems or political ecology. This leads to questions such as: how does development in and through space(s) take place from the perspective of sustainability? What are the inherent conflicts in the pursuit of social sustainability on the one hand, and the political-economic forces that prevail in real estate markets on the other?

7. Researching and improving spatial quality calls for collective learning processes, negotiation and action. This involves a transdisciplinary approach, an ethical position on social transformation and the development of interactive methods. Such an approach is possible from a perspective of social innovation considered as innovation in social relations within and among communities with the purpose of (better) satisfying human needs - in this case 'spatial quality' (Moulaert et al. 2013). Collective learning can expose the inherently social character of space and the uses of space, but can also show the way to making social relations more participative.

These dimensions of the meta-framework stress the importance of a relational approach in determining spatial quality, which can be used for three complementary diagnostic and analytical objectives: (1) identifying the 'makers' (actors, actants) of spatial qualities in their different roles, within their networks as they are socio-spatially and socio-ecologically embedded and figuring out how they interactively (re)produce space and its qualities; (2) identifying the spatial features that are relevant to the actors and actants adhering to diverse spatial quality values and using different notions of space, sustainability, etc. and how these features are qualitatively changed; (3) making a reflexive analysis of the role of the researchers, planners, designers, community developers, etc. involved in the spatial quality exercises: whose cause are they pursuing? Which ontology and theoretical perspectives have they adopted? How great is their openness to work interactively with users of space, and to use a combination of methods from different disciplines?

The meta-framework shows the potential of an integrated approach for spatial quality analysis, by making the connections between the different dimensions more relational and by stressing the agency-driven transformative character of spatial quality building in places, neighbourhoods, landscapes, public spaces, etc. In this way it follows up on the desire of designers, planners or community developers to work in a more integrative and interactive way on the improvement of spatial quality. Yet each space has its own quality challenges, and the actors making a space act within that space according to their mindsets and their institutional embeddedness. Participatory design, community building and planning approaches stress the specificity and the context of the spatial realities they 'work with'. This specificity will best be valorized if addressed in a dialogue orchestrated by an integrative approach to spatial quality as supported by the meta-framework while giving full attention to the often indirect way in which spatial quality is often idiosyncratically narrated and deconstructed by specific authors and actors in specific places and cases.

\section{Broadening the Concept of Integrative Spatial Quality}

Working towards integrative spatial quality is an epistemological and normative necessity and should lead to socio-spatially innovative and ecological theories and practices in urban design, community development and planning. It involves understanding, connecting, analysis and 
synthesis of space and spatial qualities from diverse perspectives through a relational pragmatic epistemology of physical and social forms and uses of space with the purpose of identifying transformative potentialities for socio-spatially innovative and ecological placemaking. The meta-framework sketched out in the previous section is an effort towards integration in this regard. It acknowledges the complexity of the relationship between space and place, and between environment and users; and that these fundamentally dynamic relationships are heavily influenced by (intersubjective) cultures. Such dynamic suggests that both politics of place and conceptualizations of space should be revisited by way of specific positioning towards contemporary values (e.g. environmental sustainability and justice, spatial equity, democratic decision making and oversight procedures, collective learning, interscalar harmony, etc.). In broadening the concept of spatial quality, the intention is to achieve coherence across understanding space, place- and planmaking, thereby linking theory and practice to their specific socio-spatially embedded context in order to respond to the conditions of complexity, indeterminacy and irreducible uncertainty (Bertolini 2010) that characterize the built environment.

The authors of this themed issue bring in valuable perspectives that explore the diversity of ways of broadening the concept of spatial quality. A relational epistemology - understood as knowledge that is derived through connection, response and resolution of difference (ThayerBacon 1997) — of spatial qualities requires looking into the quality of and the different spatial relationships people experience and to understand how these could enhance the de-construction of conventional beliefs and construction of new knowledge. To this purpose, the collection of papers of this themed issue proposes a user-oriented multidimensional reading of space and its qualities. It highlights the importance of ethical and political issues in urban design and planning processes, especially in terms of whether or not voices of different social groups (blind people, farmers and inhabitants of rural/urban peripheries, temporary space users such as cyclists and visitors of median spaces) have the opportunity to be expressed and taken into account. Thus, a relational epistemology of space methodologically supports the communication and use of vital knowledge that may be overlooked (or excluded) otherwise. Multiplicity, discord and dissonance but also complementarity between diverse views and theories - such as in the bicycle commuter and the Flemish open space paper-then become cornerstones in (transdisciplinary and interdisciplinary) knowledge building in urban design and planning. Moreover, and by bringing a collection of case studies together, the importance of context-dependent knowledge building processes is emphasized.

Authors in this themed issue offer an expanded view on what type of epistemology of space, its uses and transformations can inform a democratic and inclusive notion of spatial quality and how spatial quality can be co-constructed by users, analysts and designers. While mobilizing different philosophical backgrounds and competing perspectives, authors are united in their call for an integrative view of spatial quality, requiring a broadening of the theoretical core of the discipline of urban design through a productive dialogue with other disciplines about ways to understand, articulate, use and transform space.

\section{Going Beyond 'Designerly' and 'Planningly' Ways of Knowing}

In this themed issue, papers by Stefansdottir (2014), Dewaelheyns, Vanempten, Bomans, Verhoeve and Gulinck (2014), Cox, Goethals, De Meulder, Schreurs and Moulaert (2014), Tardiveau and Mallo (2014) and Sankalia (2014), as well as the paper by Heylighen and 
Herssen (2014) (part of this themed issue but published in 19:3) explore integrative spatial quality in a transdisciplinary manner. Heylighen and Herssen propose to transcend the limits of designers' 'visual thinking' about space by bringing a blind person's perception of architecture to the fore. A visit of a blind person accompanied by a researcher to a sixteenth century college building serves them as an opportunity to reveal and explore multi-sensory qualities of space. Stefansdottir further broadens this endeavour of multi-sensory perception by looking at how bicycle commuters experience aesthetic qualities of space. He does so by combining three families of theories belonging to different fields of knowledge: phenomenology of sensory perception and experience; urban design theory; and environmental aesthetics. The author rightly argues that:

Relating earlier studies on bicycling to these theories may elucidate the ways in which bicycling affects how the senses work and how perception of the environment can be interpreted in terms of aesthetic meaning. ... The importance of aesthetic features has a strong relation to expectations and attitude towards the trip. (this issue, 496)

Researching the ways in which persons with impaired vision and persons in motion experience architecture opens up new avenues for inquiry into sensory, formal and symbolic interaction between people and built environment. While sensing without vision and kinaesthetic sensing present limits to the 'usual' sensory input the subjects can process, at the same time they expand the ways in which information is handled and interpreted by feeling subjects.

By sensing the texture, warmth, sounds and smells of the building together with the blind, Heylighen and Herssen deconstruct the metaphysics of vision that grounds the formation of architectural knowledge and design process. The paper claims that while architects have mastered the use of visual language in thinking about, making and communicating designs, their 'graphicacy' (Cross 1982, 2006) has-as much as numeracy in sciences and literacy in humanities - proven to be largely insensitive to bodily experience of the built environment. The connoisseurship of the blind (see Gibson 2000) unravels not only how people with impaired vision sense space, but also how others do so, often without realizing it. The inquiry into the 'blind ways of knowing' helps Heylighen and Herssen (2014) to unpack the 'designerly ways of not knowing' and to reach beyond the conscience of the eye.

In a similar vein, Dewaelheyns, Vanempten, Bomans, Verhoeve and Gulinck question the underpinnings of geospatial analysis in spatial planning and policy making. The paper looks at two contradictory paradigms that have shaped valuation of open spaces in spatial planning. On the one hand, the 'rural paradigm' that is traditionally associated with quantitative geospatial analysis of the general economic value of the land at the macro (regional) scale is measured through its potential for agricultural production. On the other, the 'urban paradigm' that operates at micro (local) scales favours qualitative approaches to open space valuation and focuses on diverse recreational, economic, ecological, scenic and educational values that are assigned to spaces by different groups of stakeholders. Moreover, the paper claims that while the urban approach that emphasizes such evaluation criteria as proximity and sharing assigns variegated values to smaller areas of open space, such areas seem to be undervalued in the traditional rural approach (see also: de Groot 2006; Hein et al. 2006; van der Valk and van Dijk 2009). Dewaelheyns et al. mobilize the case study of Woluweveld, a rural site located at the urban fringe of Brussels, to call for bridging the gap between the urban and rural paradigm by the enrichment of top-down geospatial maps with qualitative bottom-up representations of 
diverse tangible and intangible qualities of space. Cox, Goethals, De Meulder, Schreurs and Moulaert show how a sequence of design and stakeholder workshops making use of the 'Synoikos' scenario Workshop method and socially innovative communication methods lead to better mutual understanding between different types of users of a rural/urban agro-industrial area surrounding Roeselare in West-Flanders, Belgium. In this area, according to the Thought 4 Food (T4F) Project for which this area was a lead case study, agricultural and leisure activities are 'doomed' to find an ecological equilibrium. As the authors state: "The Province of West Flanders commissioned the Flemish Land Agency to investigate options for improving the landscape's water supply, recreational attractiveness, and environmental amenities, without harming the spatial and economic needs of the local agricultural activities". Originally sounding as a 'mission impossible', the application of the updated Synoikos methodology resulted into a near consensus on the future coexistence of ecological, agricultural, economic and social values within an integrated spatial quality view for the area.

\section{Learning from the 'Illegitimate' and 'Unusual' Uses of Space}

The papers in this themed issue also trace the relationships between urban design, planning and management strategies and mundane practices of the users of space. While Heylighen and Herssen and Dewaelheyns et al. inquire into alternative ways of design and planning knowledge formation, Sankalia and Tardiveau and Mallo put theories of lived space (Lefebvre 1991) and everyday life (De Certeau 1984; Chase, Crawford and Kaliski 2008) into motion to examine how formal practices of producers and regulators of urban public spaces are challenged, but also stimulated and reformulated, by transversal tactics of public space users.

Sankalia employs a case study of picnicking on a grassed median that separates roadways in Berkeley, CA, to discuss relations between road design and engineering, connections between leisureand commercial spaces, informal uses of space and public realm enforcement. The consumption of pizza slices purchased at a busy local restaurant, that had become a common local habit bringing up to 100 students and young professionals to gather on a 3-metre wide grass strip, somewhat troubled the liberal local government of the world-famous and utterly middle-class university town. On the one hand, it was a hazardous and unlawful activity; on the other, it constituted an edgy place-making practice, enlivened a vibrant public realm, and, foremost, was good for the business. By tracing the impotence of the planning authority coupled with a liberal enforcement regime, Sankalia traces the politics of middle-class informality wherein spatially innovative practice reaffirms socio-economic status quo, and, as such, gets accommodated by the liberal city. Yet somewhat puzzlingly the author does not address the problem of air and noise quality to which this median amidst a heavy multi-lane traffic road is exposed.

Conversely, Tardiveau and Mallo examine how spatially innovative practice can bring about social change. Drawing upon the theory of assemblage (Deleuze and Guattari [1972] 2004a, [1980] 2004b; De Landa 2006) and spatial readings of habitus (Bourdieu 1997; Dovey 2005, 2010), they test the capacity of temporary urbanism (Petcou and Petrescu 2007; De Smet 2013) to transform both physical and socio-political spaces. Tardiveau and Mallo document a temporary public space project they carried out together with Architecture students on a small grassed area located between tower blocks on a deprived social housing estate in Gateshead, North-East England. In a series of indoor and outdoor events involving social tenants they explored the potentials of temporary infrastructures, everyday objects, and diverse socio-spatial 
assemblages in transforming spatial agency of the residents, as well as relations among them and the relations between them and the Gateshead Housing Company. Tardiveau and Mallo put in motion the precarious assemblages on an underused outdoor urban space and challenge the relations between 'legitimate' and 'illegitimate' spatial practices to destabilize the taken for-granted dispositions and transform socio-political relations on the council estate.

\section{Addressing Spatial Quality as a Social Learning Process}

In different but complementary ways the papers in this themed issue address strategic features of successfully reading, analyzing and building spatial quality: synergetic interaction between actors; combining types of knowledge; integrating fields of scientific knowledge; respecting time dynamics; connecting spatial scales; imagineering shared world views.

Synergetic interaction between actors. In particular the Gateshead and the T4F cases are powerful reference experiences for interaction between actors. Researchers, inhabitants and, to a less extent, housing estate managers stepwise shared insights on the desired spatial qualities, translated these into (pre)designs and/or temporary projects and installations. This required the development of a common understanding of the diversity of concerns and desires, or even a common language between participants. In T4F "Social innovation contributed to the design process as emphasis was placed on allowing an equal opportunity for people to participate and influence the design process, minimising power distortions, and stimulating collective learning by heightening the consciousness of the participants to urban experiences of other social groups".

Combining types of knowledge. This refers to the various features of spatial quality to which users of space, policy makers, researchers and other actors referred. Striking is the role of the sensory repertoire which particular users develop as a function of their own abilities and mediation with space: blind people relying on their tactile capacities, cyclists speeding through expectedly safe cycling routes, etc. While senses without vision and kinaesthetic senses present limits to the 'usual' sensory input the subjects can process, at the same time they expand the ways in which information is handled and interpreted by feeling subjects and should be added to the repertoire of senses to be taken into account in a spatial quality learning process. It is also important to stress here the links between scientific and tacit knowledge. Most sensory knowledge is tacit, but its interpretation and translation into design action relies heavily on the application of different types of scientific knowledge.

Integrating fields of scientific knowledge. The most straightforward integration of scientific spatial disciplines is implanted into the methodology that integrates spatial planning, urban design and community development through social innovation. But contributions to this themed issue also revealed the importance of, among others, psychology, sociology, anthropology, aesthetics, ecology, mobility studies, geography, hydrology, etc. in the reading, analysis and construction of spatial quality. Moreover, several contributions successfully materialize theoretical concepts into empirical or practical categories.

Respecting time dynamics. Be it in (participatory) observation or joined-up analysis, design or action research, time is important. The Synoikos method as, for example, applied in the T4F case study (rural/urban Roeselare), Synoikos, which is Greek for 'dwelling together' - is a participatory process allowing participants to formulate development strategies and initial 
project ideas. The method proved interesting as a tool for stimulating participants to assess their environment, to explore desired projects for the future, and to cooperate when projects needed to be implemented. By applying a participatory urban design Workshop seriesconsisting of several workshops - based on the Synoikos method, design and participation were combined to unlock local knowledge and to discern the environmental and landscape qualities in a more collaborative, dialogic and inclusive way. However, 'dwelling together' can only be co-creative if sufficient time is taken to analyze together, to communicate and build trust among participants, to provide moments for reflection, feedback and synthesis, as well as feed into iterative design processes. Trust building and sustained communication are also critical to planning for spatial quality initiatives in which powerful public authorities and corporate players are involved.

Connecting spatial scales. The Woluwefield is the most powerful case study showing the importance of connecting spatial scales in both analysis and collective action (policy making, collective management at the local level) in and for open space units in Flanders, Belgium. Geospatial methods used at the regional level attach less value to local and specific characteristics of small open space units, which from the perspective of the local users and community may have stronger local value significance. The latter may be revealed through a diversity of methods addressing local networks, actors, uses, etc. However, connecting scales also matters for other cases in this themed issue: the connection between the local scale of the housing estates in Gateshead with that of the wider scale of the nearby road infrastructure; accessibility of buildings from adjoining spaces for blind people; the rural/urban connections between different agricultural land uses around Roeselare in the T4F case; etc. Connecting spatial scales does not take place overnight but, again, takes time, requires exchange of information and perceptions, views on possible connections from the perspective of different users, etc.

In summary, reading, analyzing and co-constructing spatial quality needs quality time: time to work iteratively, carefully dealing with the concerns listed in this concluding section, working towards a shared understanding and vision of what exists, is desired and could be coconstructed; time that is also needed to improve methods of analysis and co-construction. Finally for now, and as stressed by the authors of the T4F paper (this theme issue), time to build the networks and forms of cooperation needed to follow-up on the trust relations and commitments made by the participants in the transdisciplinary experiences they lived together and from which they expect improvements in the spatial quality of their environments.

\section{References}

Alexander, C., S. Ishikawa, M. Silverstein, M. Jacobson, I. Fiksdahl-King, and S. Angel. 1977. A Pattern Language: Towns, Buildings, Construction. New York: Oxford University Press.

Allen, S. 1999. Pointsp Lines: Diagrams and Projects for the City. New York: PrincetonArchitectural Press. Appleyard, D., and A.

Jacobs. 1982. Toward an Urban Design Manifesto (Working Paper No. 384). Berkeley: University of California, Berkeley, Institute of Urban and Regional Development.

Austin, Wendy, Caroline Park, and Erika Goble. 2008. "From Interdisciplinary to Transdisciplinary Research: A Case Study." Qualitative Health Research 18 (4): 557-564. 
Bacon, E. 1974. The Design of Cities. New York: Penguin.

Banerjee, T. 2001. "The Future of Public Space: Beyond Invented Streets and Reinvented Places." Journal of the American Planning Association 67 (1): 9-24.

Banerjee, T., and M. Southworth, eds. 1991. City Sense and City Design: Writings and Projects of Kevin Lynch. Cambridge, MA: MIT Press.

Barnett, J. 2014. "Do Not Define Urban Design too Narrowly.” Journal of Urban Design 19 (1): 49-52.

Bentley, I. 1998. “Urban Design as an Anti-Profession.” Urban Design Quarterly 65: 15.

Bertolini, L. 2010. "Coping with the Irreducible Uncertainties of Planning: An Evolutionary Approach.” In The Ashgate Research Companion to Planning Theory: Conceptual Challenges for Spatial Planning, edited by J. Hillier and P. Healey, 413-424. Farnham: Ashgate Publishing Limited.

BonJour, L., and Ernest Sosa. 2003. Epistemic Justification: Internalism vs Externalism, Foundations vs Virtues. Oxford: Blackwell.

Bourdieu, P. 1997. Outline of a Theory of Practice. Cambridge: Cambridge University Press.

Bridge, G. 2013. “A Transactional Perspective on Space.” International Planning Studies 18 (3-4): 304320.

Carmona, M. 2014. "The Place-Shaping Continuum: A Theory of Urban Design Process.” Journal of Urban Design 19 (1): 2-36.

Carmona, M., C. De Magalha es, and M. Edwards. 2002. "Stakeholder Views on Value and Urban Design." Journal of Urban Design 7 (2): 145-169.

Chase, J., M. Crawford, and J. Kaliski. 2008. Everyday Urbanism. New York: Monacelli Press.

Cooper, D., ed. 1999. Epistemology: The Classic Readings. Oxford: Blackwell.

Cox, V., M. Goethals, B. De Meulder, J. Schreurs, and F. Moulaert. 2014. "Beyond Design and Participation: The Thought for Food Project in Flanders, Belgium." Journal of Urban Design 19 (4): $412-435$.

Cozens, P. M. 2008. "New Urbanism, Crime and the Suburbs: A Review of the Evidence." Urban Policy and Research 26 (4): 429-444.

Crawford, M. 1995. "Contesting the Public Realm: Struggles over Public Space in Los Angeles." Journal of Architectural Education 49 (1): 4-9.

Cross, N. 1982. “Designerly Ways of Knowing.” Design Studies 3 (4): 221-227.

Cross, N. 2006. Designerly Ways of Knowing. London: Springer-Verlag.

Crysler, G., S. Cairns, and H. Heynen, eds. 2012. Handbook Architectural Theory. London: Sage.

Cullen, G. 1961. Townscape. London: Architectural Press.

Cuthbert, A. 2011. "Urban Design and Spatial Political Economy." In Companion to Urban Design, edited by T. Banerjee and A. Loukaitou-Sideris, 84-96. London: Routledge.

De Certeau, M. 1984. The Practice of Everyday Life. Berkeley: University of California Press.

de Groot, R. 2006. "Function-Analysis and Valuation as a Tool to Assess Land use Conflicts in Planning for Sustainable, Multi-Functional Landscapes." Landscape and Urban Planning 75 (3-4): 175-186. 
De Jong, M., and J. M. Van Der Voordt, eds. 2002. Ways to Study and Research Urban, Architectural and Technical Design. Delft: Delft University Press.

De Landa, M. 2006. A New Philosophy of Society: Assemblage Theory and Social Complexity. London and New York: Continuum.

De Smet, A. 2013. "The Role of Temporary Use in Urban (Re)Development: Examples from Brussels." Brussels Studies: The E-Journal for Academic Research on Brussels. Accessed November 13, 2013. http:// brusselsstudies.be/medias/publications/BruS72EN.pdf

Deleuze, G., and F. Guattari. [1972] 2004a. Anti-Oedipus. Vol. 1 of Capitalism and Schizophrenia. Translated by Brian Massumi. London and New York: Continuum.

Deleuze, G., and F. Guattari. [1980] 2004b. A Thousand Plateaus. Vol. 2 of Capitalism and Schizophrenia. Translated by B. Massumi. London and New York: Continuum.

Dewaelheyns, V., E. Vanempten, K. Bomans, A. Verhoeve, and H. Gulinck. 2014. "The Fragmentation Bias in Valuing and Qualifying Open Space.”Journal of Urban Design 19 (4): 436-455.

Dovey, K. 1999. Framing Places. Mediating Power in Built Form. London: Routledge.

Dovey, K. 2005. "The Silent Complicity of Architecture." In Habitus: A Sense of Place, edited by J. Hillier and E. Rooksby, 283-296. Hants: Ashgate.

Dovey, K. 2010. Becoming Places: Urbanism/Architecture/Identity/Power. Oxon: Routledge.

Ewing, R., and S. Handy. 2009. "Measuring the Unmeasurable: Urban Design Qualities Related to Walkability." Journal of Urban Design 14 (1): 65-84.

Forester, J. 1999. The Deliberative Practitioner: Encouraging Participatory Planning Processes. London: MIT Press.

Gibson, E. J. 2000. "Perceptual Learning in Development: Some Basic Concepts." Ecological Psychology 12 (4): 295-302.

Gosling, David, and B. Maitland. 1984. Concepts of Urban Design. London/New York: Academy Editions/Martin's Press.

Healey, P. 2006. "Relational Complexity and the Imaginative Power of Strategic Spatial Planning." European Planning Studies 14 (4): 525-546.

Healey, P. 2008. "Making Choices that Matter: The Practical Art of Situated Strategic Judgements in Spatial Strategy-Making." In Empowering the Planning Fields: Ethics, Creativity and Action, edited by J. Van den Broeck, F. Moulaert, and S. Oosterlynck, 23-41. Leuven: Acco.

Healey, P. 2009. "The Pragmatic Tradition in Planning Thought." Journal of Planning Education and Research 28 (3): 277-292.

Hein, L., K. van Koppen, R. S. de Groot, and E. C. van Ierland. 2006. "Spatial Scales, Stakeholders and the Valuation of Ecosystem Services.” Ecological Economics 57 (2): 209-228.

Heylighen, A., and J. Herssens. 2014. "Designerly Ways of Not Knowing: What Designers Can Learn about Space from People Who are Blind.” Journal of Urban Design 19 (3): 317-332.

Hillier, J. 2011. "Strategic Navigation Across Multiple Planes: Towards a Deleuzean-Inspired Methodology for Strategic Spatial Planning.” Town Planning Review 82 (5): 503-527.

Hoch, C. J. 2007. "Pragmatic Communicative Action Theory." Journal of Planning Education and Research 26 (3): 272-283. 
Hollis, M. 2002. The Philosophy of Social Science. Cambridge: Cambridge University Press.

Inam, A. 2002. "Meaningful Urban Design: Teleological/Catalytic/Relevant.” Journal of Urban Design 7 (1): $35-58$.

Jacobs, J. [1961] 1974. Death and Life of American Cities: The Failure of Town Planning. Middlesex: Penguin Books.

Khan, Ahmed Z. 2010. "Rethinking Doxiadis ' Ekistical Urbanism: Sustainability and Globalization as a Dialectical Framework for Design." Positions 2010 (1): 6-39.

Khan, Ahmed Z. 2011. "When History Becomes the Corpus for Designerly Way of Thinking." In Historiography of Architecture, edited by P. Vandal, 23-29. Lahore: THAAP.

Khan, Ahmed Z. 2013. "On Design and Politics of Co-Producing Public Space: The Long Marches and the Reincarnation of the 'Forecourt' of the Pakistani Nation." International Journal of Islamic Architecture 2 (1): 125-156.

Khan, Ahmed Z., F. Moulaert, and J. Schreurs. 2013. "Epistemology of Space: Exploring Relational Perspectives in Planning, Urbanism, and Architecture." International Planning Studies 18 (3-4): 287303.

Khan, Ahmed Z., H. Vandevyvere, and K. Allacker. 2013. "Design for the Ecological Age: Rethinking the Role of Sustainability in Architectural Education." Journal of Architectural Education 67 (2): 175185 .

Klein, J., T. Mitcham, and C. Frodeman. 2010. The Oxford Handbook of Interdisciplinarity. Oxford: Oxford University Press.

Krieger, Alex. 2009. "Where and How Does Urban Design Happen?” In Urban Design, edited by Alex Krieger and William S. Saunders, 113-130. Minneapolis/London: University of Minnesota.

Lefebvre, H. 1991. The Production of Space. Oxford and Cambridge, MA: Blackwell. LoukaitouSideris, A. 2012. "Addressing the Challenges of Urban Landscapes: Normative Goals for Urban Design.” Journal of Urban Design 17 (4): 467-484.

Lynch, K. 1960. The Image of the City. Cambridge, MA: Technology Press and Harvard University Press.

Lynch, K. 1981. Good City Form. Cambridge, MA: MIT Press.

Madanipour, A. 2006. "Roles and Challenges of Urban Design.” Journal of Urban Design 11 (2): 173193.

Madanipour, A., ed. 2010. Whose Public Space? London: Routledge.

Madanipour, A. 2013. "Researching Space, Transgressing Epistemic Boundaries." International Planning Studies 18 (3-4): 372-388.

Margolin, V., and R. Buchanan. 1995. The Idea of Design. Cambridge, MA: The MIT Press.

Marshall, S. 2012. "Science, Pseudo-Science and Urban Design.” Urban Design International 17 (4): 257-271.

Massey, D. 2005. For Space. London: Sage. Mehta, V. 2014. "Evaluating Public Space.” Journal of Urban Design 19 (1): 53-88.

Miciukiewicz, K., F. Moulaert, A. Novy, S. Musterd, and J. Hillier. 2012. "Introduction: Problematising Urban Social Cohesion: A Transdisciplinary Endeavour.” Urban Studies 49 (9): 1855-1872. 
Moore, S. A., and A. Karvonen. 2008. "Sustainable Architecture in Context: STS and Design Thinking." Science Studies 21 (1): 29-46.

Mostafavi, M., and G. Doherty, eds. 2010. “Ecological Urbanism.” Baden: Lars Muller Publishers.

Moulaert, F., and D. Cassinari. 2014. "Enabling Transdisciplinary Research on Social Cohesion in the City: The Social Polis Experience.” In Research Methods in Spatial Planning. A Case-Based Guide to Research Design, edited by E. Da Silva, P. Healey, N. Harris, and P. Van den Broeck. London: Routledge.

Moulaert, F., and A., Mehmood. 2014. "Towards Social Holism: Social Innovation, Holistic Research Methodology and Pragmatic Collective Action in Spatial Planning." In Research Methods in Spatial Planning: A Case-Based Guide to Research Design, edited by E. Da Silva, P. Healey, N. Harris, and P. Van den Broeck. London: Routledge.

Moulaert, F., and B. Van Dyck. 2013. "Framing Social Innovation Research: A Sociology of Knowledge Perspective." In The International Handbook on Social Innovation. Collective Action, Social Learning and Transdisciplinary Research, edited by F. Moulaert, et al., 466-479. Cheltenham: Edward Elgar.

Moulaert, F., B. Van Dyck, A. Z. Khan, and J. Schreurs. 2013. "Building a Meta-Framework to ‘Address' Spatial Quality.” International Planning Studies 18 (3-4): 389-409.

Ostrom, E. 2007. "Sustainable Ecological Systems: An Impossibility?" Presented at the 2007 Annual Meetings of the American Association for the Advancement of Science. Science and Technology for Sustainable Well-Being. San Francisco, February 15-19. Petcou, C., and D.

Petrescu. 2007. "Acting Space. Transversal Notes, On-The-Ground Observations and Concrete Questions for Us All." In Urban Act. A Handbook for Alternative Practice, edited by aaaPEPRAV, 319-328. Paris: aaa-PEPRAV.

Rapoport, A. 1970. “The Study of Spatial Quality.” Journal of Aesthetic Education 4 (4): 81-95.

Rapoport, A. 1982. The Meaning of the Built Environment: A Nonverbal Communication Approach. Beverly Hills, CA: Sage.

Sankalia, T. 2014. "The Median Picnic: Street Design, Urban Informality and Public Space Enforcement." Journal of Urban Design 19 (4): 473-495.

Scheer, B. 2011. "Metropolitan Form and Landscape Urbanism." In Companion to Urban Design, edited by T. Banerjee and A. Loukaitou-Sideris, 611-618. London: Routledge.

Schreurs, J., L. Boudry, et al. 2006. "Ontwerpend onderzoek: een constante zorg.” In Inzet, Opzet, Voorzet. Stadsprojecten in Vlaanderen, 118-131. Antwerp-Apeldoorn: Garant Uitgevers.

Schreurs, J. 2007. "Communicating Quality: Words and Images." ARQ Architectural Research Quarterly 11 (3-4): 325-333.

Segers, R., P. Van den Broeck, A. Z. Khan, F. Moulaert, J. Schreurs, B. De Meulder, K. Miciukiewicz, G. Vigar, and A. Madanipour, eds. 2013. Handboek Ruimtelijke Kwaliteit. Brussels: Academic and Scientific Publishers.

Servillo, L., and J. Schreurs. 2013. "Pragmatism and Research by Design: Epistemological Virtues and Methodological Challenges.” International Planning Studies 18 (3-4): 358-371. 
Sitte, C. [1889] 1965. City Planning According to Artistic Principles. Translated by George R. Collins and Christiane Crasemann Collins. New York: Random House.

Southworth, M. 2014. "Public Life, Public Space, and the Changing Art of City Design." Journal of Urban Design 19 (1): 37-40.

Stefansdottir, H. 2014. "A Theoretical Perspective on How Bicycle Commuters Might Experience Aesthetic Features of Urban Space.” Journal of Urban Design 19 (4): 496-510.

Sternberg, E. 2000. "An Integrative Theory of Urban Design." Journal of the American Planning Association 66 (3): 265-278.

Stokols, D., K.L. Hall, B. K. Taylor, and R.P. Moser. 2008. “The Science of Team Science: Overview of the Field and Introduction to the Supplement." American Journal of Preventive Medicine 35 (2S): S77-S89.

Tardiveau, A., and D. Mallo. 2014. "Unpacking and Challenging Habitus: An Approach to Temporary Urbanism as a Socially Engaged Practice.” Journal of Urban design 19 (4): 456-472.

Thayer-Bacon, B. J. 1997. "The Nurturing of a Relational Epistemology.” Educational Theory 47 (2): 239-260.

Thrift, N. 2003. "Space: The Fundamental Stuff of Human Geography." In Key Concepts in Geography, edited by S. Holloway, S. Rice, and G. Vallentine, 95-107. London: Sage.

Tuana, Nancy. 2013. "Embedding Philosophers in the Practices of Science: Bringing Humanities to the Sciences." Synthese 190 (11): 1955-1973.

Van den Broeck, P., M. Abdelwahab, K. Miciukiewicz, and J. Hillier. 2013. "On Analysing Space from a Strategic-Relational Institutionalist Perspective: The Cultural Park for Children in Cairo." International Planning Studies 18 (3-4): 321-341.

van der Valk, A., and T. van Dijk. 2009. Regional Planning for Open Space. London: Routledge.

Wagner, Caroline S., J. D. Roessner, K. Bobb, J. T. Thompson Klein, K. W. Boyack, J. Keyton, I. Rafols, and K. Borner. 2011. "Approaches to Understanding and Measuring Interdisciplinary Scientific Research (IDR): A Review of the Literature.” Journal of Informetrics 165 (2011): 14-26.

Waldheim, C., ed. 2006. The Landscape Urbanism Reader. New York, NY: Princeton Architectural Press.

Yaneva, A. 2012. Mapping Controversies in Architecture. Farnham: Ashgate. 